\begin{tabular}{|c|c|c|}
\hline Case Reports i & \multicolumn{2}{|c|}{ Case Rep Gastroenterol 2013;7:388-391 } \\
\hline Gastroenterology & $\begin{array}{l}\text { DOI: 10.1159/000355348 } \\
\text { Publisned online: september 9, } 2013\end{array}$ & $\begin{array}{l}\text { (c) } 2013 \text { S. Karger AG, Basel } \\
1662-0631 / 13 / 0073-0388 \$ 38.00 / 0 \\
\text { www.karger.com/crg }\end{array}$ \\
\hline & \multicolumn{2}{|c|}{$\begin{array}{l}\text { This is an Open Access article licensed under the terms of the Creative Common } \\
\text { Attribution-NonCommercial } 3.0 \text { Unported license (CC BY-NC) (www.karger.com/OA } \\
\text { license), applicable to the online version of the article only. Distribution permitted for non } \\
\text { commercial purposes only. }\end{array}$} \\
\hline
\end{tabular}

\title{
Liver Unidentified Bright Object in a Septic Patient
}

\author{
Daniel Peternac ${ }^{a} \quad$ Michael Andreas Patak $^{b} \quad$ Christoph Gubler $^{c}$ \\ ${ }^{a}$ Division of Gastroenterology and Hepatology, Cantonal Hospital of Münsterlingen, \\ Division of ${ }^{b}$ Diagnostic and Interventional Radiology and ${ }^{c}$ Gastroenterology and \\ Hepatology, University Hospital Zürich, Switzerland
}

\section{Key Words}

Liver hemangioma $\cdot$ Systemic inflammation $\cdot$ Changing appearance $\cdot$ Ultrasound

\begin{abstract}
The typical sonographic appearance of liver hemangiomas is a well-demarcated hyperechoic mass with homogeneous echodensity. Focal liver lesions may change their ultrasound characteristics over time. We present a case of dynamic pattern of liver hemangiomas during a state of systemic inflammation.

(c) 2013 S. Karger AG, Basel
\end{abstract}

\section{Introduction}

Ultrasound is usually the first examination in the work-up for elevated liver enzymes. Hemangiomas and cysts represent the majority of incidentally detected lesions in asymptomatic patients without liver disease. Depending on the sonographic features, additional imaging studies, i.e. contrast-enhanced ultrasound, computed tomography and magnetic resonance imaging (MRI), may further characterize the lesion. The following case illustrates that liver nodules may show a dynamic pattern over time and highlights the importance of comparing with previous pictures.

\section{Case Report}

A 63-year-old patient was hospitalized due to pneumonia of the left lower lobe. He presented with fever $\left(39.4^{\circ} \mathrm{C}\right)$ and leukocytosis of $13 \times 10^{9} / \mathrm{l}$, fulfilling the criteria for systemic inflammatory response syndrome (SIRS). Treatment with ceftriaxone was initiated and he was referred to our clinic for ultrasound of the liver owing to elevated liver enzymes.

Daniel Peternac, MD

Division of Gastroenterology and Hepatology

Cantonal Hospital of Münsterlingen

$\mathrm{CH}-8596$ Münsterlingen (Switzerland)

E-Mail daniel.peternac@stgag.ch 
Peternac et al.: Liver Unidentified Bright Object in a Septic Patient

This imaging procedure (Toshiba Aplio XG, using a curved 3.5-MHz probe) showed intense hyperechoic, homogenous and well-defined nodules in segment VII/VIII $(3.1 \times 2 \mathrm{~cm}, 0.9 \times$ $0.6 \mathrm{~cm}$ and $0.7 \times 0.7 \mathrm{~cm})$, segment V/VI $(1.5 \times 1.5 \mathrm{~cm})$ and another in the caudate lobe $(1.8 \times$ $2.2 \mathrm{~cm}$ ) (fig. 1). For better characterization and to rule out septic lesions, MRI (GE Horizon, Milwaukee, Wisc., USA) with an intravenous liver-specific contrast agent (Resovist ${ }^{\circledR}$, Schering, Berlin, Germany) was subsequently performed in a standardized manner [1]. The lesions at the aforementioned locations were all confirmed as being hemangiomas without any inflammatory or malignant characteristics (fig. 2). The patient subsequently recovered from the pneumonia and was discharged after 10 days. A follow-up ultrasound at 3 months demonstrated all lesions with a typical hypo- to isoechoic pattern (fig. 3a). One year before multiple hemangiomas had been incidentally detected on conventional B-mode ultrasound. These ultrasound images from the referral hospital were available, demonstrating identical sonographic features (fig. $3 \mathrm{~b}$ ) as found after recovering from SIRS and pneumonia. An additional contrast-enhanced ultrasound on Aplio XG using low mechanical index after injection of $1.4 \mathrm{ml}$ of the contrast agent SonoVue ${ }^{\circledR}$ showed for the lesion in segment VIII a typical peripheral nodular arterial enhancement with a portal venous centripetal filling consistent with typical hemangioma. Within the following year, three unenhanced ultrasound studies showed unchanged size and imaging findings of all hemangiomas.

\section{Discussion}

This case demonstrates the dynamic characteristics on ultrasound of hepatic hemangiomas during a state of systemic inflammation due to pneumonia. To our knowledge there is no similar report in the literature. The typical sonographic appearance of liver hemangiomas is a hyperechoic mass with uniform echodensity and dorsal sound enhancement. However, $7-15 \%$ of hemangiomas show an iso- to hypoechoic pattern [2]. In the presence of fatty liver, hemangiomas are often imaged as hypoechoic lesions [3]. Hence, if patients develop steatosis, the sonographic characteristics of hemangiomas may change during the time course, appearing either as hyperechoic and indistinguishable or markedly hypoechoic compared to the surrounding parenchyma. Contrast-enhanced ultrasound can improve the diagnostic yield of undetermined lesions and can serve as an additional tool [4].

Chevallier et al. [5] described hyperechoic liver nodules associated with acquired porphyria cutanea tarda. The biopsy of such a lesion showed inflammatory changes with porphyrin crystals and macrovacuolar steatosis. After successfully treating the underlying condition with chloroquine, weekly phlebotomies and alcohol cessation, the sonographic findings completely resolved. This course is similar to our case, in whom the hemangiomas returned to a hypo- to isoechoic pattern after pneumonia had been adequately treated. SIRS may have been the key factor, triggering local inflammatory changes in the hemangiomas and leading to the marked echogenic appearance. We did not perform a biopsy, which might have proven this hypothesis. The underlying hyperdynamic systemic circulation seems to be an additional explanation, probably leading to enhanced perfusion of the liver and the hemangiomas, respectively. The cardiac index was not determined, but was expected to be high.

We conclude that in situations with systemic inflammation (SIRS, sepsis), focal liver lesions may change their sonographic appearance. Most inflammatory lesions, e.g. liver abscesses or emboli, can probably be distinguished because they generally show a hypoechoic pattern. At least hemangiomas transiently appear hyperechoic and return to the appearance as before the inflammatory state. If available, comparison with previous pictures is helpful in differentiating such lesions. 


\begin{tabular}{l|l}
\hline DOI: $10.1159 / 000355348$ & $\begin{array}{l}\text { C } 2013 \text { S. Karger AG, Bar. B } \\
\text { www.karger.com/crg }\end{array}$ \\
\hline
\end{tabular}

Peternac et al.: Liver Unidentified Bright Object in a Septic Patient

\section{References}

1 Bastati-Huber N, Prosch H, Baroud S, Magnaldi S, Schima W, Ba-Ssalamah A: New developments in MRI of the liver (in German). Radiologe 2011;51:680-687.

$>2$ Dietrich CF, Mertens JC, Braden B, Schuessler G, Ott M, Ignee A: Contrast-enhanced ultrasound of histologically proven liver hemangiomas. Hepatology 2007;45:1139-1145.

3 Konno K, Ishida H, Sato M, Komatsuda T, Ishida J, Naganuma H, Hamashima Y, Watanabe S: Liver tumors in fatty liver: difficulty in ultrasonographic interpretation. Abdom Imaging 2001;26:487-491.

4 Bernatik T, Seitz K, Blank W, Schuler A, Dietrich CF, Strobel D: Unclear focal liver lesions in contrastenhanced ultrasonography - lessons to be learned from the DEGUM multicenter study for the characterization of liver tumors. Ultraschall Med 2010;31:577-581.

-5 Chevallier P, Bahadoran P, Buckley MJ, Hebuterne X, Diaine B, Chevallier A, Coussement A: Hepatic multinodular focal fatty metamorphosis in acquired porphyria cutanea tarda. Sonographic, CT, and MRI features. Clin Imaging 1998;22:418-421.

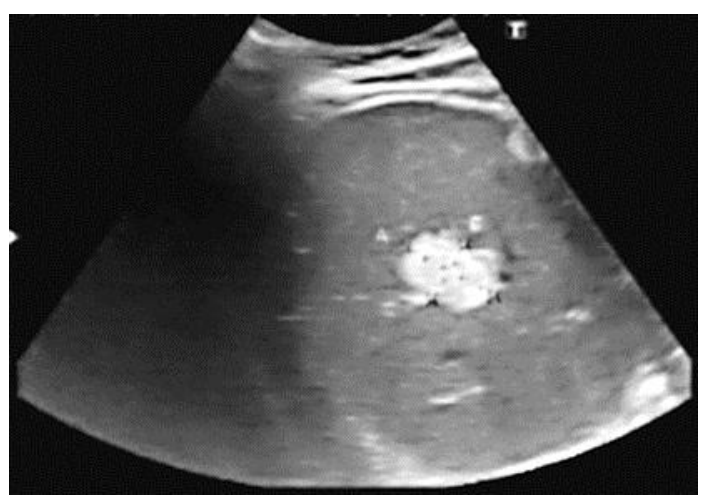

Fig. 1. Intense hyperechoic lesion in liver segment VIII. 


\begin{tabular}{l|l}
\hline Case Rep Gastroenterol 2013;7:388-391 \\
\hline DOI: 10.1159/000355348 & $\begin{array}{l}\text { @ 2013 S. Karger AG, Basel } \\
\text { www.karger.com/crg }\end{array}$ \\
\hline
\end{tabular}

Peternac et al.: Liver Unidentified Bright Object in a Septic Patient
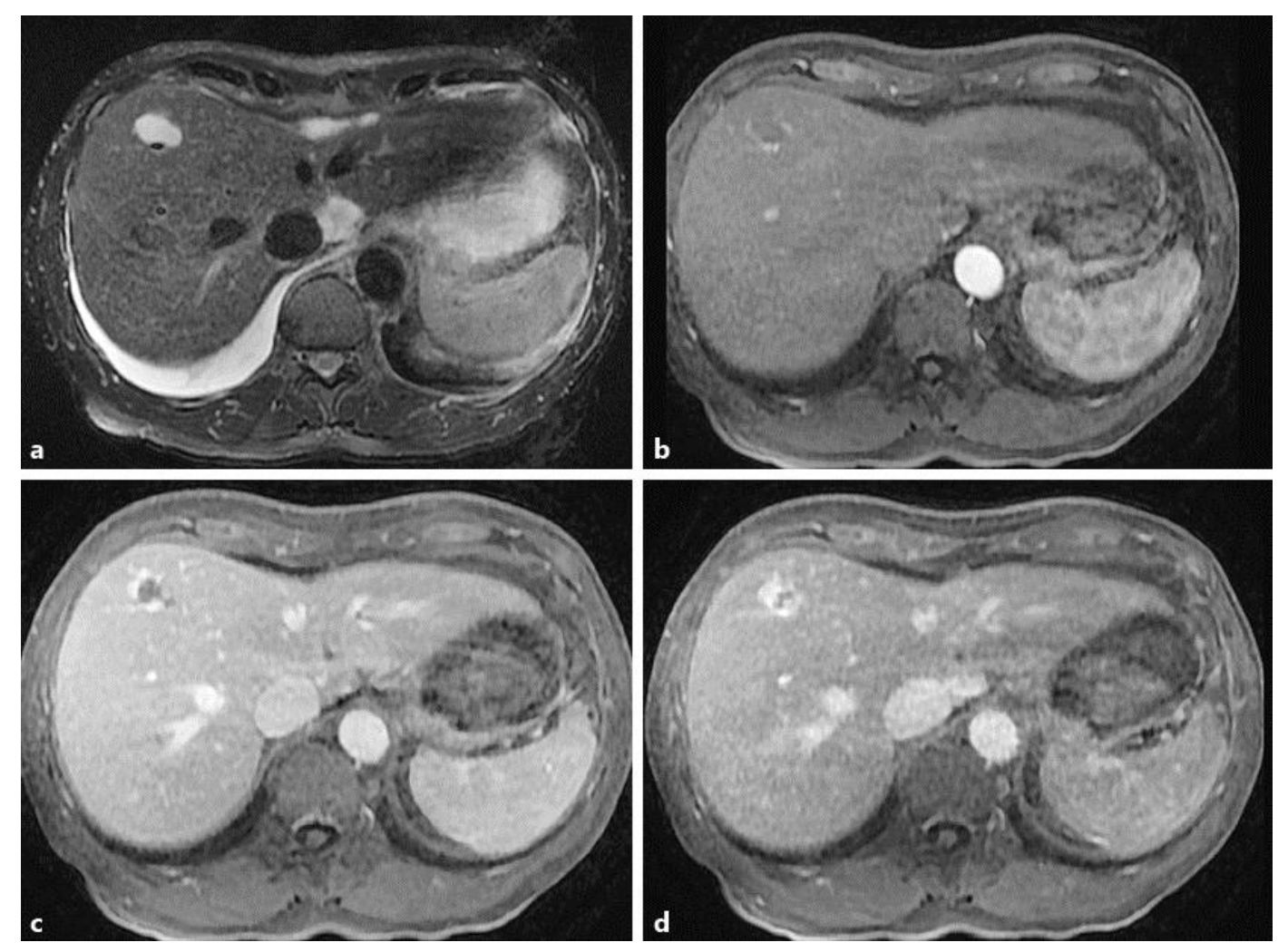

Fig. 2. a MRI of a typical hemangioma in liver segment VIII. T2-weighted imaging showed a bright hyperintense lesion ('light bulb phenomenon'). After injection of contrast, the arterial phase (b) showed a typical rim-like peripheral enhancement with gradual centripetal contrast uptake in the portal-venous phase (c) and in the late phase (d).
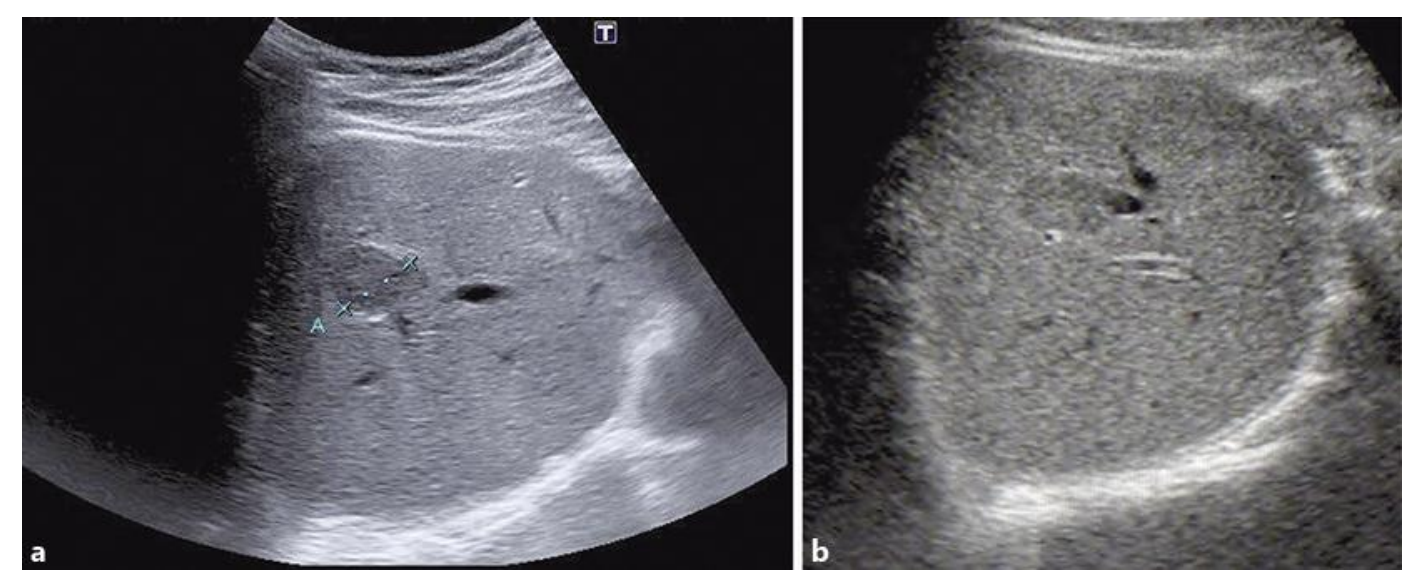

Fig. 3. a Well-defined, hypoechoic lesion in liver segment VIII. b First documented picture of the hypoechoic lesion in liver segment VIII. 